\title{
UMA EXPERIÊNCIA DA ENGENHARIA DIDÁTICA NO PROCESSO DE HIBRIDIZAÇÃO DA SEQUÊNCIA DE LEONARDO
}

\author{
UNA EXPERIENCIA DE INGENIERÍA DIDÁCTICA EN EL PROCESO DE \\ HIBRIDACIÓN DE LA SECUENCIA LEONARDO
}

\author{
AN EXPERIENCE OF DIDACTIC ENGINEERING IN THE \\ HYBRIDIZATION PROCESS OF THE LEONARDO SEQUENCE
}

DOI: 10.22481/rbba.v10i02.9560

Milena Carolina dos Santos Mangueira Instituição Federal de Educação, Ciência e Tecnologia do Ceará - Brasil

LATTES: http://lattes.cnpq.br/9192608272738688

ORCID: https://orcid.org/0000-0002-4446-155X

Endereço eletrônico: milenacarolina24@gmail.com

Renata Passos Machado Vieira Instituição Federal de Educação, Ciência e Tecnologia do Ceará - Brasil

LATTES: http://lattes.cnpq.br/0166320689075492

ORCID: https://orcid.org/0000-0002-1966-7097

Endereço eletrônico: re.passosm@gmail.com

Francisco Regis Vieira Alves Instituição Federal de Educação, Ciência e Tecnologia do Ceará - Brasil

LATTES: http://lattes.cnpq.br/3288513376230522 ORCID: https://orcid.org/0000-0003-3710-1561 Endereço eletrônico: fregiis@ifce.edu.br

Paula Maria Machado Cruz Catarino Universidade de Trás-os-Montes e Alto Douro - UTAD, Portugal Endereço eletrônico: pcatarino2@gmail.com 


\section{RESUMO}

Diante de investigações referentes ao ensino de sequências numéricas, tem-se o interesse de abordar a sequência de Leonardo aplicada aos números híbridos, observando pouca abordagem na literatura matemática e na área de ensino. $\mathrm{O}$ estudo se pautou no ensino sistemático do processo de hibridização da sequência de Leonardo, com base na Engenharia Didática e Teoria das Situações Didáticas, que fundamentaram teórica e metodologicamente esta pesquisa. A sequência foi aplicada no Instituto Federal de Educação, Ciência e Tecnologia do Estado do Ceará com a participação de oito estudantes. A coleta de dados aconteceu durante a disciplina de História da Matemática do curso de Licenciatura em Matemática, de forma virtual, por meio da plataforma do Google Meet, uma vez que a época de aplicação se deu durante a pandemia do coronavírus (Covid-19). Tem-se que os principais resultados foram analisados e validados de forma interna, com base na Engenharia Didática e Teoria das Situações Didáticas. Tem-se que os principais resultados foram analisados e validados de forma interna, com base na Engenharia Didática e Teoria das Situações Didáticas e apontam que as situações promoveram o ensino do processo de hibridização da sequência de Leonardo, permitindo uma compreensão histórica e evolutiva da História da Matemática.

Palavras-chave: Engenharia Didática. Números Híbridos. Sequência de Leonardo. Teoria das Situações Didáticas.

\section{RESUMEN}

Frente a las investigaciones relacionadas con la enseñanza de secuencias numéricas, existe interés en acercarse a la secuencia de Leonardo aplicada a números híbridos, notando que hay poco abordaje en la literatura matemática y en el área de la enseñanza. El estudio se basó en la enseñanza sistemática del proceso de hibridación de la secuencia Leonardo, con base en la Ingeniería Didáctica y la Teoría de Situaciones Didácticas, que fundamentalizó teórica y metodológicamente esta investigación. La secuencia se aplicó en el Instituto Federal de Educación, Ciencia y Tecnología del Estado de Ceará con la participación de ocho estudiantes. La recogida de datos se realizó durante el curso de Historia de las Matemáticas de la carrera de Grado en Matemáticas, de forma virtual, a través de la plataforma Google Meet, ya que el momento de la aplicación se produjo durante una pandemia de coronavirus (Covid-19). Los principales resultados se 
formaron y validaron internamente, con base en la Ingeniería Didáctica y la Teoría de Situaciones Didácticas. Los principales resultados fueron producidos y validados internamente, con base en la Ingeniería Didáctica y la Teoría de Situaciones Didácticas y señalan que las hipótesis promovieron la enseñanza del proceso de hibridación de la secuencia de Leonardo, permitiendo una comprensión histórica y evolutiva de la Historia de las Matemáticas.

Palabras clave: Ingeniería Didáctica. Números híbridos. Secuencia de Leonardo. Teoría de las situaciones didácticas.

\begin{abstract}
In view of investigations related to the teaching of numerical sequences, it is interesting to approach the Leonardo sequence applied to hybrid numbers, noting that there is little approach in the mathematical literature and in the teaching area. The study was based on the systematic teaching of the hybridization process of the Leonardo sequence, based on Didactic Engineering and Theory of Didactic Situations, which theoretically and methodologically supported this research. The sequence was applied at the Federal Institute of Education, Science and Technology of the State of Ceará with the participation of eight students. Data collection took place during the Mathematics History course of the Mathematics Degree course, virtually, through the Google Meet platform, since the time of application occurred during the coronavirus pandemic (Covid-19). The main results were analyzed and validated internally, based on Didactic Engineering and Didactic Situations Theory. The main results were analyzed and validated internally, based on Didactic Engineering and Didactic Situations Theory and point out that the situations promoted the teaching of the hybridization process of the Leonardo sequence, allowing a historical and evolutionary understanding of History of Mathematics.
\end{abstract}

Keywords: Didactic Engineering. Hybrid Numbers. Leonardo's Sequence. Theory of Didactic Situations.

\title{
1. INTRODUÇÃO
}

Percebe-se que, atualmente, muitas pesquisas envolvendo a investigação do ensino e aprendizagem de conceitos matemáticos são encontradas na Didática da Matemática (ALVES; MARINHO, 2017). Sendo assim, destaca-se a presença dos pesquisadores franceses, alinhando Revista RBBA Revista Binacional Brasil Argentina Vol. 10, num. 2, dez/2021, p. 271-297 


\section{UMA EXPERIÊNCIA DA ENGENHARIA DIDÁTICA NO PROCESSO DE}

HIBRIDIZAÇÃO DA SEQUÊNCIA DE LEONARDO

metodologias com o viés de analisar a dimensão do conhecimento matemático, por meio de sistemas didáticos em associação à processos de ensino e aprendizagem (ARTIGUE, 1988).

No cenário das pesquisas entorno dos livros de História da Matemática, encontra-se o estudo do conceito de sequência, como é o caso da sequência da Fibonacci. Logo, os números da sequência de Fibonacci são relacionados à sequência de Leonardo, apresentada inicialmente por Catarino e Borges (2019), sendo então pouco abordada na literatura (VIEIRA; ALVES; CATARINO, 2019). Esta sequência possui a recorrência $L e_{n}=L e_{n-1}+L e_{n-2}+1$, para $n \geq 2$, $n \in \square$, com $L e_{0}=1$ e $L e_{1}=1$ os seus valores iniciais e gerando os números $1,1,3,5,9,15,25$, 41, 67, 109, 177. E, sendo $L e_{n}=2 F_{n+1}-1$, sua relação com os números da sequência de Fibonacci.

À vista disso, é realizado um estudo referente à evolução histórica e matemática da sequência de Leonardo, transfigurando num conteúdo a ser repassado aos estudantes em cursos de formação inicial de professores de Matemática. Porém, durante o proceso de transformar a sequência de Leonardo a ser um conteúdo a ser ensinado, é possível que existam determinados obstáculos de como desenvolver, matemáticamente, a situação proposta e como validá-la, devendo ser superados por meio do seu processo de evolução. Com isso, ressalta-se os aspectos epistemológicos, cognitivos e didáticos, com o viés de modelar essa investigação, com base na metodologia de pesquisa da Engenharia Didática (ED) em associação com a teoria de ensino da Teoria das Situações Didáticas (TSD), referente ao ensino da sequência de Leonardo.

Diante disso, establece-se a pergunta norteadora: como desenvolver situações didáticas oportunizadas a investigar sobre o processo de hibridização da sequência de Leonardo, de seus teoremas e de suas propriedades matemáticas?

De modo a superar os obstáculos diagnosticados, tais como: utilização do método indutivo e qual estratégia utilizar para resolver a situação proposta, são desenvolvidos os objetivos gerais e específicos, de modo a elencar os elementos de ordem epistemológica, cognitiva e didática, baseados na ED. Logo, tem-se o objetivo geral: discutir elementos de um estudo sistemático, fundamentado na ED em associação com a TSD, referente ao processo de hibridização da sequência de Leonardo, visando explorar as suas propriedades matemáticas.

Com base no objetivo geral da pesquisa, foram traçados os objetivos específicos, sendo esses: 1) investigar os teoremas e propriedades matemáticos referentes à sequência de Leonardo e o seu processo de hibridização; 2) analisar e discutir situações de ensino sobre o processo de 


\section{HIBRIDIZAÇÃO DA SEQUÊNCIA DE LEONARDO}

hibridização da sequência de Leonardo; 3) constatar o desenvolvimento histórico-evolutivo da sequência de Leonardo e o seu processo de hibridização, com base em situações-problema abordadas em sala de aula.

Devido ao contexto da pandemia do coronavírus (Covid-19), as aulas foram planejadas e aplicadas remotamente, sendo portanto, realizado acordos com os estudantes participantes desta pesquisa. Para isso, foi utilizada a plataforma do Google Meet, dentre outros recursos computacionais, visando facilitar o atual processo de ensino e aprendizagem.

Destaca-se que este trabalho representa um recorte da pesquisa realizada no Mestrado Acadêmico do Programa de Pós-graduação em Ensino de Ciências e Matemática (PGECM) no Instituto Federal de Educação, Ciência e Tecnologia do Estado do Ceará (IFCE), possuindo o parecer aprovado no Comitê de Ética em Pesquisa (CEP) (parecer: 4.141.910). Assim, foram desenvolvidas situações didáticas de ensino, visando instigar os estudantes ao raciocínio intuitivo para compreenderem os conceitos matemáticos abordados.

\section{ANÁLISES PRELIMINARES}

Iniciou-se nesta seção o processo de construção do referencial teórico, baseado no conteúdo da hibridização da sequência de Leonardo, com aporte na ED e TSD. Por conseguinte, são exploradas e analisadas algumas situações de ensino inerentes ao objeto matemático em estudo, com o viés de alcançar o objetivo geral desta pesquisa, definido através de sua respectiva problemática.

Ao construir o campo epistêmico-matemático podemos evidenciar os trabalhos de Catarino e Borges (2019) e Vieira, Alves e Catarino (2019); Alves et al. (2020) os quais apresentam estudos em torno da sequência de Leonardo. Quanto aos números híbridos, Özdemir (2018) é o pioneiro a abordar esses números, posteriormente Carvalho (2019) apresenta uma visualização geométrica para esses números. E ainda, nos trabalhos de Catarino (2019), CerdaMorales (2018), Szynal-Liana (2018a), Szynal-Liana e Wloch (2019, 2018b), Mangueira et al. (2020), Mangueira, Alves e Catarino (2020) e Kızılateş (2020) pode-se encontrar o processo de hibridização de algumas sequências lineares recursivas.

O estudo da ED foi abordado pela primeira vez no trabalho de Artigue (1988, 2002, 2018, 2015) posteriormente, pode-se destacar os trabalhos de Alves (2016), Pommer (2013), Almouloud (2007) e, permitindo a compreensão da metodologia de pesquisa, valorizando as Revista RBBA | Revista Binacional Brasil Argentina Vol. 10, num. 2, dez/2021, p. 271-297 
práticas dos docentes, e o seu respectivo processo de ensino e aprendizagem, por meio de situações didáticas, elaboradas com base nas dificuldades identificadas em torno do objeto de estudo.

A teoria de ensino, TSD, foi apresentado inicialmente por Guy Brousseau (2006, 2002, 2000, 1997, 1995, 1982), e ressalta-se trabalhos relevantes baseados nas pesquisas de Souza e Lima (2014), Teixeira; Passos (2013) e Pais (2002). Com isso, ressalta-se a importância da sua utilização no período da elaboração e da análise das situações didáticas de ensino fundamentadas na ED.

\section{ENGENHARIA DIDÁTICA}

A Engenharia Didática é uma metodología de pesquisa surgida nos anos $80 \mathrm{em}$ decorrência da vertente francesa da Didática Matemática, a Engenharia Didática associa-se o seu trabalho didático ao ofício de um engenheiro que, para realizar um determinado projeto se baseia em conhecimentos científicos da sua área, mas, ao mesmo tempo, utilizando objetos mais complexos. Dessa forma, essa metodologia de pesquisa qualitativa, possui um design para que seja possível alcançar um determinado objetivo matemático, por meio de investigações e fundamentada em diversas fases, sejam elas: análises preliminares, concepção e análise a priori, experimentação e análise a posteriori e validação, estudando problemas oriundos da aprendizagem de conhecimentos específicos da matemática.

Objetivando transfigurar o conteúdo matemático alinhado no objeto de estudo num conteúdo a ser ensinado, surge-se a necessidade de realizar a transposição didática. Com isso, Artigue (2002, p. 28), define a transposição como sendo

a possível viabilidade do conteúdo que se deseja promover, considerando as
leis que governam o funcionamento do sistema de ensino. Tentamos prever as
deformações pelas quais é provável que sofram; tenta-se garantir que o objeto
possa viver e, portanto, se desenvolver dentro do sistema de ensino sem mudar
drasticamente sua natureza ou se tornar corrompido (tradução nossa).

Para isso, tem-se a utilização da metodologia de pesquisa da ED, fornecendo um quadro teórico para elaborar, desenvolver e analisar as situações de ensino propostas. Assim, temos a aplicação dessa metodologia com âmbito na Didática da Matemática, com o viés de contribuir no desenvolvimento das investigações voltadas para a realização de situações didáticas de ensino. À vista disso, o professor investigador tem a possibilidade de considerar os aspectos 


\section{HIBRIDIZAÇÃO DA SEQUÊNCIA DE LEONARDO}

epistemológicos, cognitivos e didáticos do objeto matemático em estudo, diante da proposta aplicada aos estudantes participantes desse processo de investigação voltado para a área de ensino. Porém, ressalta-se que alguns obstáculos poderão ocorrer no decorrer da aplicação, devendo superá-los e sanadas as restrições identificadas (ALVES, 2016). Segundo Artigue (1988), esta metodologia possui o seu trabalho comparado ao de um engenheiro, elaborando estratégias de acordo com a dificuldade de cada estudante em análise, envolvendo a problemática identificada, segundo a identificação do obstáculo epistemológico.

Logo, o professor deverá considerar a transposição referente ao saber matemático das situações de ensino ocorridas em sala de aula, onde dessa forma considera-se o objeto de estudo matemático, bem como um grupo de estudo em análise. Com isso, tem-se então a divisão da ED em quatro fases: análises preliminares, concepção e análise a priori, experimentação e análise a posteriori e validação.

As análises preliminares referem-se ao levantamento do referencial teórico em torno do objeto matemático, construindo assim o campo epistêmico-matemático para que haja uma fundamentação teórico ao serem abordadas em sala de aula por meio de situações de ensino (ARTIGUE, 2015). É nesse momento que ocorre a construção dos aspectos epistemológicos, cognitivos e didáticos do conteúdo. De acordo com Artigue (1995), esta etapa é analisada em três dimensões: em relação a epistemologia, comparando-a com um jogo; cognição, sendo então relacionada com as características dos estudantes em análise; e a didática, referente ao sistema de ensino.

A concepção e análise a priori é o momento em que são definidas as variáveis, sendo então microdidáticas ou macrodidáticas. A microdidática, é dada pelos possíveis comportamentos dos estudantes durante as situações didáticas. A macrodidática realiza o direcionamento da pesquisa. Logo, nessa fase, observa-se a necessidade de utilizar uma metodologia de ensino, elaborando situações-problema, em que fornece aos estudantes a sua participação ativa durante este processo de aprendizagem (POMMER, 2013). Para orientar a definição das variáveis Almouloud e Silva (2012) apresenta três pontos de extrema importância, são eles: descrever as escolhas efetuadas no local comparando-as com as situações didáticas; analisar a situação proposta para o aluno, em função das possibilidades de ação, seleção, decisão, controle e validação; prever possíveis comportamentos e tentar demonstrar como esta fase permitirá controlá-los. Assim, o professor/pesquisador deve internalizar a possibilidade de transformar o conhecimento científico em conteúdo a ser ensinado e devem ser elaborados

Revista RBBA $\mid$ Revista Binacional Brasil Argentina Vol. 10, num. 2, dez/2021, p. 271-297 


\section{HIBRIDIZAÇÃO DA SEQUÊNCIA DE LEONARDO}

hipóteses didáticas e situações-problema que serão aplicadas aos alunos. Com isso, é então utilizada a TSD, com base em sua teoria e suas respectivas etapas das situações didáticas, voltadas ao ensino.

A experimentação ocorre com a aplicação das situações de ensino desenvolvidas na fase anterior, para que então essas possam ser analisadas na fase seguinte. Entretanto, esse momento é apoiado à utilização de determinados recursos para que possam ser realizados registros dessa fase, tais como gravações de áudio, registros fotográficos e entre outros. Diante disso, torna-se necessário mais uma vez, a utilização de uma teoria de ensino, visando analisar os comportamentos dos participantes da pesquisa durante a experimentação da pesquisa, de modo similar ao ocorrido na fase anterior.

Ressalta-se que é nesta fase que deve ser estabelecido um contrato didático (BROUSSEAU, 1982), que consiste em um acordo pedagógico entre alunos e professor durante a interação no ambiente de ensino, onde o docente e o discente assumem as suas respectivas responsabilidades, sendo este, portanto, os comportamentos esperados dos estudantes pelos professores e vice-versa. A análise a posteriori e validação, são as etapas finais da ED que segundo Pommer (2013, p.26) a análise a posteriori:

(...) se caracteriza pelo tratamento dos dados colhidos e a confrontação com a análise a priori, permitindo a interpretação dos resultados e em que condições as questões levantadas foram respondidas. Assim, é possível analisar se ocorrem e quais são as contribuições para a superação do problema, caracterizando a generalização local que permitirá a validação interna do objetivo da pesquisa.

E ainda, é realizado a validação, sendo então a partir de uma comparação entre o que foi definido na análise a priori com o que foi coletado na análise a posteriori, para que sejam validadas as hipóteses durante a investigação. Para essa validação, existem dois métodos, a saber: interna e externa. $\mathrm{Na}$ validação interna a análise ocorre somente com os estudantes participantes da ED. Na validação externa, é realizada uma comparação dos estudantes participantes da ED, com outros que não utilizaram (ALMOULOUD, 2007).

\section{TEORIA DAS SITUAÇÕES DIDÁTICAS}

A TSD é uma teoria de ensino foi iniciada na década de 60 na França, iniciada por Brousseau (1986) com vista em estudos sobre o construtivismo em pedagogia, oriundos da teoria da epistemologia genética de Piaget. Destaca-se a interação durante a aprendizagem dos

Revista RBBA $\mid$ Revista Binacional Brasil Argentina Vol. 10, num. 2, dez/2021, p. 271-297 


\section{HIBRIDIZAÇÃO DA SEQUÊNCIA DE LEONARDO}

estudantes de matemática, o estudo do objeto matemático e o professor como sendo o meio didático nesse processo. $\mathrm{O}$ ambiente da sala de aula é organizado, estimulando as interações entre o professor, o estudante e o saber. Sendo assim, o professor tem o papel de organizar a forma como o conhecimento será repassado (BROUSSEAU, 2000). E ainda, Freitas (2015) relata que essa teoria é considerada como uma referência no processo de aprendizagem matemática, pois envolve o aluno, o professor e o conhecimento matemático em torno da valorização dos saberes mobilizados pelo aluno e seu envolvimento na construção desses conhecimentos.

Diante disso, associaremos a TSD à ED, sendo analisados os comportamentos dos estudantes em análise, realizando planos de ações durante o processo de ensino e aprendizagem, sendo dividida em quatro situações: ação, formulação, validação e institucionalização. Tem-se então a Figura 1, apresentando a junção dessas duas metodologias, permitindo que a TSD, auxilie na análise das concepções elaboradas. Inicialmente tem-se a situação fundamental, em que realiza o diagnóstico da análise epistemológica do objeto matemático, sendo portanto subdividida em duas parte: resource design, em que aplica as situações de ensino durante a fase da experimentação; e experiment, onde ocorre a aplicação das situações de ensino elaboradas na etapa anterior. Ressalta-se que durante essa subdivisão, ocorre a inserção da TSD na ED.

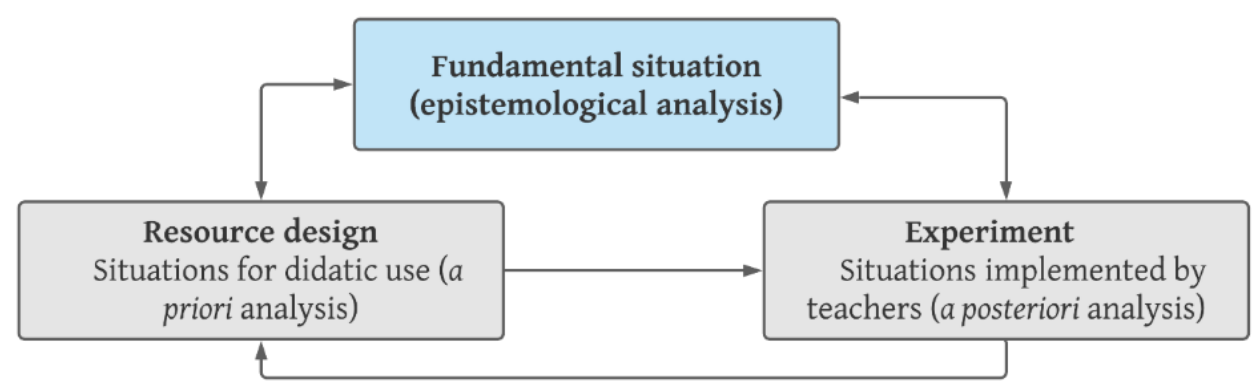

Figura 1: Inserção da TSD na ED

Fonte: Elaborado pelos autores com base em Tempier, 2016, p.264.

O professor, assume então o papel de ofertar situações de ensino, com o intuito de aperfeiçoar a autonomia do estudante. Já o aluno, depara-se com as situações de ensino propostas pelo professor, instigando-os a resolver e convidar os demais participantes para discutir as questões matemáticas, buscando assim construir o seu próprio conhecimento (BROUSSEAU, 1996).

Revista RBBA $\mid$ Revista Binacional Brasil Argentina Vol. 10, num. 2, dez/2021, p. 271-297 


\section{HIBRIDIZAÇÃO DA SEQUÊNCIA DE LEONARDO}

$\mathrm{Na}$ situação de ação, o professor apresenta as atividades propostas aos estudantes, devendo esses participantes buscar em seus respectivos conhecimentos prévios para que seja possível resolvê-las. Essas atividades são dispostas por meio de situações-problema, em que segundo Pais (2002), essas possuem o formato de questões discursivas, oportunizando a construção do próprio conhecimento dos estudantes (BROUSSEAU, 2002). E ainda, de acordo com Almouloud (2007, p.37), tem-se que:

Uma boa situação de ação não é somente uma situação de manipulação livre ou que exija uma lista de instruções para seu desenvolvimento. Ela deve permitir ao aluno julgar o resultado de sua ação e ajustá-lo, se necessário, sem a intervenção do mestre, graças à retroação do milieu. Assim, o aluno pode melhorar ou abandonar seu modelo para criar um outro: a situação provoca assim uma aprendizagem por adaptação.

$\mathrm{Na}$ situação de formulação, é apresentado interações existentes em determinada atividade proposta, resultando em uma estratégia de resolução, seja ela: escrita ou oral, em linguagem natural ou matemática. Essa situação é caracterizada pela troca de saberes entre alunos e outros indivíduos. Texeira e Passos (2013, p.165) relata que nesta situação:

Ocorre troca de informação entre o aluno e o milieu, com a utilização de uma linguagem mais adequada, sem a obrigatoriedade do uso explícito de linguagem matemática formal, podendo ocorrer ambiguidade, redundância, uso de metáforas, criação de termos semiológicos novos, falta de pertinência e de eficácia na mensagem, dentro de retroações contínuas; os alunos procuram modificar a linguagem que utilizam habitualmente, adequando-a às informações que devem comunicar.

Na situação de validação, os estudantes deverão demonstrar, por meio de métodos e técnicas matemáticas, para que sejam validadas as suas respectivas conjecturas (BROUSSEAU, 2006). Teixeira e Passos (2013) diz que nesta fase os alunos têm que tentar convencer os interlocutores da veracidade das afirmações, utilizando demonstrações matemáticas.

Nas situações de institucionalização, é o momento em que o professor entre em ação, revelando a real intenção da atividade proposta, discutindo ainda as formulações realizadas (SOUZA; LIMA, 2014). Teixeira e Passos (2013, p. 166) diz que:

O professor, aí, retoma a parte da responsabilidade cedida aos alunos, conferindo-lhes o estatuto de saber ou descartando algumas produções dos alunos e definindo, assim, os objetos de estudo por meio da formalização e da generalização. É na institucionalização que o papel explícito do professor é manifestado: o objeto é claramente oferecido ao aluno.

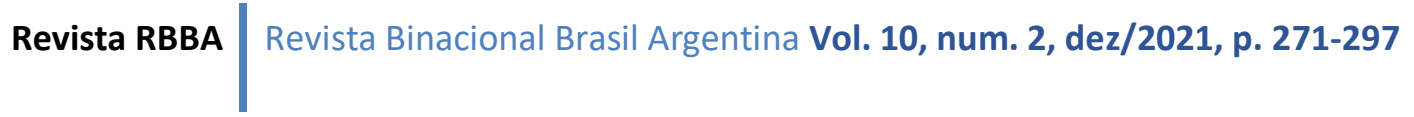




\section{UMA EXPERIÊNCIA DA ENGENHARIA DIDÁTICA NO PROCESSO DE}

HIBRIDIZAÇÃO DA SEQUÊNCIA DE LEONARDO

Portanto, a TSD concederá o estabelecimento de uma modelagem de situação didática que permite ao aluno participar de forma efetiva da elaboração e fixação da cognição, estabelecendo condições para desenvolver novos conhecimentos embasados nas experiências adquiridas com meio e com os integrantes das sessões didáticas em que foram participantes.

\section{CAMPO EPISTÊMICO-MATEMÁTICO}

Nesta seção tem-se como objetivo descrever o processo de hibridização da sequência de Leonardo. Para isto, é então realizado um levantamento bibliográfico, referente ao objeto de estudo da sequência de Leonardo e do conjunto dos números híbridos, para que seja então dado início ao processo de hibridização desta sequência. Contudo, tem-se que a sequência de Leonardo é discutida inicialmente em Catarino (2019), na qual é apresentada como uma sequência recorrente de números inteiros que está relacionado com a sequência de Fibonacci e de Lucas que podem sem aplicadas em quase todos os campos da ciência. Historicamente, Alves et al. (2020) acredita que esses números foram estudados por Leonardo de Pisa, conhecido por Leonardo Fibonacci devido à grande similaridade desta sequência com a sequência de Fibonacci, não sendo, portanto, comprovado em nenhum trabalho na literatura, devido à escassez de pesquisas referentes a essa sequência. Com isso, a sequência de Leonardo satisfaz a seguinte relação de recorrência: $L e_{n}=L e_{n-1}+L e_{n-2}+1, n \geq 2, n \in \square$, com $L e_{0}=1 \mathrm{e} L e_{1}=1$ os seus valores iniciais, e ainda, Catarino (2019) apresenta outra recorrência de satisfaça os números de Leonardo, seja ela: $L e_{n+1}=2 L e_{n}-L e_{n-2}, n \geq 2$, mantendo os mesmos valores iniciais. Pode-se estabelecer uma relação entre os números de Leonardo com os de Fibonacci, expressa por: $L e_{n}=2 F_{n+1}-1$. Em Vieira, Alves e Catarino (2019), pode-se encontrar um estudo a respeito das relações recorrentes bidimensionais desses números a partir do seu modelo unidimensional.

Outrora, o conjunto dos números híbridos é apresentado inicialmente por Özdemir (2018), na qual é definida como a junção de três sistemas numéricos bem distintos e estando combinados um com o outro, sendo eles: números complexos, duais e hiperbólicos.

Definição 1. Um número híbrido é definido por Özdemir (2018): $\mathrm{K}=\left\{a+b i+c \varepsilon+d h: a, b, c, d \in \square, i^{2}=-1, \varepsilon^{2}=0, h^{2}=1, i h=-h i=\varepsilon+1\right\}$.

A partir disso, é possível realizar algumas operações com os números híbridos, tais como: adição, subtração, multiplicação por escalar e o produto dos números híbridos. 


\section{HIBRIDIZAÇÃO DA SEQUÊNCIA DE LEONARDO}

Apresentando ainda, propriedades inerentes, tais como: caráter do número híbrido, conjugado norma e forma matricial.

Tendo conhecimento da definição dos números híbridos e da sequência de Leonardo, é possível realizar o processo de hibridização destes números, na qual consiste em associar esse conjunto numérico à sequência. Esse procedimento matemático vem sendo realizado a outras sequências, o que podemos ver nos trabalhos de Catarino (2019), Cerda-Morales (2018), Szynal-Liana (2018a), Szynal-Liana e Wloch (2019; 2018b), Mangueira et al. (2020), Mangueira, Alves e Catarino (2020) e Kızılateş (2020).

Definição 2. O número híbrido de Leonardo é definido como: $H L e_{n}=L e_{n}+L e_{n+1} i+L e_{n+2} \varepsilon+L e_{n+3} h$, sendo $H L e_{0}=1+i+3 \varepsilon+5 h$ e $H L e_{1}=1+3 i+5 \varepsilon+9 h$ seus termos iniciais.

Definição 3. A relação de recorrência dos números híbridos de Leonardo, para $n \geq 2$, é dada por: $H L e_{n}=H L e_{n-1}+H L e_{n-2}+1$, ou ainda, $H L e_{n+1}=2 H L e_{n}-H L e_{n-2}$.

A partir da relação de recorrência dos híbridos de Leonardo é possível apresentar sua equação característica, como: $x^{3}-2 x^{2}+1=0$, possuindo três raízes, sejam elas: $x_{1}=\frac{1+\sqrt{5}}{2}$, $x_{2}=\frac{1-\sqrt{5}}{2}$ e $x_{3}=1$. E ainda, podemos apresentar uma relação entre os números híbridos de Fibonacci (Cerda-Morales, 2018) com os de Leonardo.

Proposição 1. A relação entre esses os números híbridos de Fibonacci e Leonardo é apresentada como: $H L e_{n}=2 H F_{n+1}-(1+i+\varepsilon+h)$.

Teorema 1. A função geradora dos números híbridos de Leonardo é dada por: $G_{H L e_{n}}(x)=\frac{\left(H L e_{0}+H L e_{1} x\right)(1-2 x)+H L e_{2} x^{2}}{\left(1-2 x+x^{3}\right)}$.

Além disso, é possível explorar a existência da fórmula de Binet que possibilita encontrar o $n$-ésimo termo da sequência, sem depender da relação de recorrência. Vale ressaltar que, para obter essa fórmula utiliza-se a relação dos números híbridos de Leonardo com os híbridos de Fibonacci.

Teorema 2. Para $n \geq 0$, temos que a fórmula de Binet para os números híbridos de Leonardo é dada como: $H L e_{n}=\frac{x_{1}\left[2 A x_{1}^{n}-(1+i+\varepsilon+h)\right]+x_{2}\left[(1+i+\varepsilon+h)-2 B x_{2}^{n}\right]}{x_{1}-x_{2}}$, 
onde $x_{1}$ e $x_{2}$ são as raízes da equação característica e $A=\left(H F_{1}-H F_{0} x_{2}\right)$ e $B=\left(H F_{1}-H F_{0} x_{1}\right)$.

De modo análogo a definição da recorrência dos números híbridos de Leonardo é possível obter uma nova recorrência para os termos negativos da sequência híbrida de Leonardo.

Definição 4. A fórmula de recorrência dos números híbridos de Leonardo para o campo dos números inteiros não positivos, com $n \in \square$, é dada por: $H L e_{-n}=H L e_{-n+2}-H L e_{-n+1}-(1+i+\varepsilon+h), \quad$ ou ainda, $H L e_{-n}=2 H L e_{-n+2}-H L e_{-n+3}$. Sendo $H L e_{-1}=-1+i+\varepsilon+3 h$ e $H L e_{-2}=1-i+\varepsilon+h$ seus termos iniciais.

Com o intuito de investigar e explorar essas propriedades e teoremas matemáticos, foram selecionados alguns desses conceitos, visando realizar uma transposição didática deste conteúdo, abordado em artigos de Matemática Pura. Assim, serão elaboradas situações didáticas, com suporte da TSD, visando a compreensão dos estudantes em torno deste objeto de estudo matemático, além de instigar o lado intuitivo e investigativo dos alunos.

\section{CONCEPÇÃO DAS SITUAÇÕES DIDÁTICA}

A concepção da situação didática parte do processo de hibridização da sequência de Leonardo com o intuito de transformá-lo em um conteúdo a ser ensinado em sala de aula, temse esse objetivo pois o processo de hibridização de sequências lineares recursivas vem sendo desenvolvido recentemente e apenas no âmbito da Matemática Pura. Não obstante, é levantado hipótese didática referente ao objeto matemático apresentado, fundamentado na ED com o suporte da TSD, com o intuito de formular uma hipótese didática, com o viés de explorar e investigar os teoremas e propriedades desenvolvidos de nesta pesquisa e transformando-os em um contexto existente em sala de aula. Segundo os epistemológicos, esse fato é definido como uma transposição didática (BROUSSEAU, 1997). O conceito de transposição didática foi concebido por Chevallard (1998) com o intuito de distinguir os conceitos de natureza apenas científica dos escolares.

Com isso, a partir das variáveis definidas, microdidáticas ou macrodidáticas, utilizaremos nesta pesquisa a variável microdidática, com o intuito que o docente preveja o comportamento dos estudantes e quais possíveis obstáculos poderão ocorrer durante a situação didática. E ainda, é necessária uma conexão entre os processos matemáticos sobre a 
hibridização da sequência de Leonardo com as situações-problema. Ressalta-se que, na exploração deste objeto matemático é necessário um conhecimento matemático básico para realizar a validação dos teoremas pelo princípio da indução matemática.

\section{ANÁLISE A PRIORI DAS SITUAÇÕES DIDÁTICAS}

A partir do que foi apresentado anteriormente, no campo epistêmico matemático, em torno do processo de hibridização dos números de Leonardo, sua recorrência, sua relação com os números híbridos de Fibonacci e sua fórmula de Binet, é elaborado duas situações didáticas de ensino fundamentadas na TSD com o intuito de prever o possível comportamento dos alunos nas fases de ação, formulação e validação, e ainda, do parecer do professor na fase de institucionalização. Nesta fase, é selecionada a variável didática a qual será utilizada nesta pesquisa, sendo, portanto, a microdidática. Com isso, a seguir temos as situações-problema proposta.

Situação-problema 1: Com base nos estudos referente à sequência de Leonardo e no conjunto dos números híbridos, é então introduzido o processo de hibridização desta sequência, possuindo a recorrência $H L e_{n}=H L e_{n-1}+H L e_{n-2}+(1+i+\varepsilon+h)$ ou $H L e_{n+1}=2 H L e_{n}-H L e_{n-2}$, $n \geq 2$. E ainda, tem-se a definição dos números híbridos de Leonardo sendo $H L e_{n}=L e_{n}+L e_{n+1} i+L e_{n+2} \varepsilon+L e_{n+3} h$. Com isso, defina uma nova recorrência para a obtenção dos termos da sequência híbrida de Leonardo para o campo dos números inteiros não positivos.

Nessa primeira situação-problema, na situação de ação, deve-se buscar inicialmente os números híbridos de Leonardo para o campo dos inteiros não positivos, e ainda, encontrar uma recorrência que satisfaça esses números. Durante a formulação, os estudantes deverão inicialmente trabalhar com os números de Leonardo, realizando uma extensão para os números negativos de Leonardo, para então substitui-los na fórmula de um número híbrido, $H L e_{n}=L e_{n}+L e_{n+1} i+L e_{n+2} \varepsilon+L e_{n+3} h$ e, consequentemente, encontrar os números híbridos de Leonardo para o campo dos números inteiros não positivos. E ainda, deverá encontrar um padrão entre esses números com o intuito de encontrar uma fórmula de recorrência que satisfaça a esses números. Na fase de validação, os estudantes deverão mostrar que a fórmula de recorrência encontrada é válida para os números híbridos negativos de Leonardo. Vale salientar 


\section{HIBRIDIZAÇÃO DA SEQUÊNCIA DE LEONARDO}

que, é possível encontrar duas fórmulas de recorrência para os números híbridos inteiros não positivos, uma vez que, são apresentadas duas recorrências para os números positivos.

Por fim, na institucionalização, o professor retoma a situação didática e conferi as respostas dos alunos, ressaltando que a partir de dois conteúdos matemáticos distintos pode realizar uma ligação entre ambos e gerar um novo conteúdo a ser explorado.

Situação-problema 2: Dada a relação dos números híbridos de Leonardo com o de Fibonacci $H L e_{n}=2 H F_{n+1}-(1+i+\varepsilon+h)$ e a fórmula de Binet dos números híbridos de Fibonacci, $H F_{n}=\frac{A x_{1}^{n}-B x_{2}^{n}}{x_{1}-x_{2}}$, sendo $A=\left(H F_{1}-H F_{0} x_{2}\right)$ e $B=\left(H F_{1}-H F_{0} x_{1}\right)$, é possível obter uma função que encontra os termos dessa sequência híbrida sem utilizar a recorrência? Fórmula esta conhecida pela Fórmula de Binet de Leonardo.

Na situação de ação desta situação problema, deve-se buscar a fórmula de Binet para os números híbridos de Leonardo, será relacionado a fórmula de Binet para os números de Fibonacci com a relação existente entre esses dois números híbridos. Na situação de formulação, os estudantes deverão perceber que a partir da fórmula de Binet de Fibonacci, $H F_{n}=\frac{A x_{1}^{n}-B x_{2}^{n}}{x_{1}-x_{2}}$, pode-se encontrar $H F_{n+1}$, somando apenas uma unidade em seu índice, e assim, substituir essa fórmula encontrada na relação entre os números híbridos de Leonardo e os números híbridos Fibonacci, $H L e_{n}=2 H F_{n+1}-(1+i+\varepsilon+h)$ e, após realizar manipulações algébricas resultará em uma nova fórmula, conhecida como fórmula de Binet. Na situação de validação, os estudantes deverão utilizar o princípio de indução finita, comprovando a validade desta fórmula.

Por fim, na institucionalização, o professor retomará a situação conferindo os resultados apresentados, evidenciará que a existência de relações entres os números híbridos de Leonardo e os números híbridos de Fibonacci e como essas relações são importantes para resultados futuros.

\section{EXPERIMENTAÇÃO}

É na fase de experimentação que é realizado a aplicação da situação didática, por meio das situações-problema, com o intuito de consolidar o contrato didático. É nesse momento que 
é executado o que foi planejado na análise a priori, segundo Coutinho e Almouloud (2008, pp. 67-68), tem-se:

\begin{abstract}
A fase de experimentação é clássica: é o momento de se colocar em funcionamento todo o dispositivo construído, corrigindo-o se necessário, quando as análises locais do desenvolvimento experimental identificam essa necessidade, o que implica em um retorno à análise a priori, em um processo de complementação. Ela é seguida de uma fase de análise a posteriori que se apoia no conjunto de dados recolhidos durante a experimentação: observações realizadas sobre as sessões de ensino e as produções dos alunos em sala de aula ou fora dela. Esses dados são, às vezes, completados por dados obtidos pela utilização de metodologias externas: questionários, entrevistas individuais ou em pequenos grupos, realizadas em diversos momentos do ensino.
\end{abstract}

Com isso, nesta fase foi realizada a aplicação de três situações-problema à oito alunos do Instituto Federal de Educação, Ciência e Tecnologia do Ceará (IFCE), campus Fortaleza, no ano de 2020, que estavam matriculados na disciplina de História da Matemática do curso de Licenciatura em Matemática, no período do primeiro semestre do referido ano (2020.1). Durante a aplicação seria importante o contato com os estudantes participantes, porém devido ao contexto da pandemia do coronavírus (Covid-19), as aulas presenciais foram paralisadas, oferecendo o ensino remoto por meio da plataforma do Google Meet. Assim, as aulas e atividades propostas, foram planejadas para acontecerem virtualmente, realizando um acordo de convivência com os estudantes participantes.

A escolha do recurso computacional foi pelo fato de ser uma ferramenta livre durante a pandemia, e de fácil manuseio e acesso, permitindo ainda a instalação de diversos complementos visando facilitar o ensino e aprendizagem ocorridos em sala de aula. Assim, para representar o quadro branco foi utilizado o Jamboard, presente no Google e de livre acesso. As gravações das aulas foram intermediadas pelo software OBS, após a autorização dos estudantes participantes, permitindo realizar, posteriormente, uma análise minuciosa dos dados coletados. Ressalta-se que algumas situações-problema foram enviadas para o WhatsApp do professor, pelo motivo de apresentar um melhor foco da imagem fornecida do celular do estudante.

Vale salientar que, a elaboração e a análise dessas atividades, foram fundamentadas na TSD, realizando registros da tela do computador e gravações das aulas, ambos com o consentimento e aprovação dos discentes envolvidos. E ainda, deve-se ressaltar a colaboração dos alunos ao enviar as situações-problema resolvidos contribuindo com o resultado da pesquisa.

Revista RBBA $\mid$ Revista Binacional Brasil Argentina Vol. 10, num. 2, dez/2021, p. 271-297 


\section{ANÁLISE A POSTERIORI E VALIDAÇÃO INTERNA}

Nesta fase é analisado as situações didáticas desenvolvidas pelos estudantes, investigando o processo de hibridização da sequência, despertando a curiosidade nos alunos com o intuito de resolverem as atividades propostas para efetivar o contrato didático. A TSD é utilizada para realizar discussões dessas situações, serão analisados cada uma das fases dessa metodologia de ensino. Com isso, a aplicação se iniciou com a apresentação da lista de situações-problema e com a orientação aos alunos que haja interação entre si, pois segundo Oliveira (2018, p.179) os alunos buscarão "sistematizar uma estratégia de resolução para, em seguida, formular argumentos que possam ser validados posteriormente”. Por fim, concluindo a análise, é realizado a validação dos dados, no que concerne em uma comparação dos resultados discutidos pelos estudantes com o que foi apresentado na análise a priori, a partir dessa comparação os resultados obtidos serão validados ou refutados.

As situações-problemas ofertadas direcionam os alunos para conhecerem inicialmente o conjunto dos números híbridos e a sequência de Leonardo, para então, conhecer o processo de hibridização desta sequência e ainda realizar sua extensão para campo dos inteiros não positivos e, consequentemente, a obtenção de uma nova recorrência. Os estudantes também conhecerão uma relação entre os números híbridos de Fibonacci com os números híbridos de Leonardo e perceberão que a partir dessa relação é possível encontrar a fórmula de Binet dos números híbridos de Leonardo. Vale salientar que, durante a fase de experimentação foi utilizado o princípio da indução finita para validar os resultados obtidos.

Na situação-problema 1, o objetivo geral era encontrar os números híbridos de Leonardo para o campo dos inteiros positivos e não positivos, e ainda, encontrar uma recorrência que seja válida para esses números inteiros não positivos. Com isso, foi apresentada a definição das recorrências da sequência de Leonardo e a definição dos números híbridos, dando um suporte teórico aos estudantes, com o intuito de que eles possam resolver a atividade proposta. Nesse sentido, os alunos tendo conhecimento dos números de Leonardo e obtendo a definição dos números híbridos logo substituíram os termos de Leonardo na definição e encontraram os números híbridos de Leonardo para os inteiros positivos (ver Figura 2).

Revista RBBA $\mid$ Revista Binacional Brasil Argentina Vol. 10, num. 2, dez/2021, p. 271-297 
1)

Número hibrido de Leonardo

$H L_{e_{n}}=L_{e_{n}}+L_{e_{n+1}} i+L_{e_{n+2}} \varepsilon+L_{n+3} h$ onde

mimeros de Leonurdo sat

$H L_{e_{b}}=1+i+3 \varepsilon+5 h$

$H L \ell_{1}=1+3 i+5 \varepsilon+9 h$

$H L l_{2}=3+5 i+9 \varepsilon+15 h$

Figura 2: Fase de ação e formulação pelo aluno A- Situação-problema 1

Fonte: Dados da pesquisa.

Assim, o aluno A percebeu que ao realizar manipulações algébricas em uma das recorrências dos números híbridos de Leonardo é possível realizar a extensão desses números híbridos para o lado esquerdo, obtendo os números híbridos negativos de Leonardo, o que é possível identificar na Figura 3.

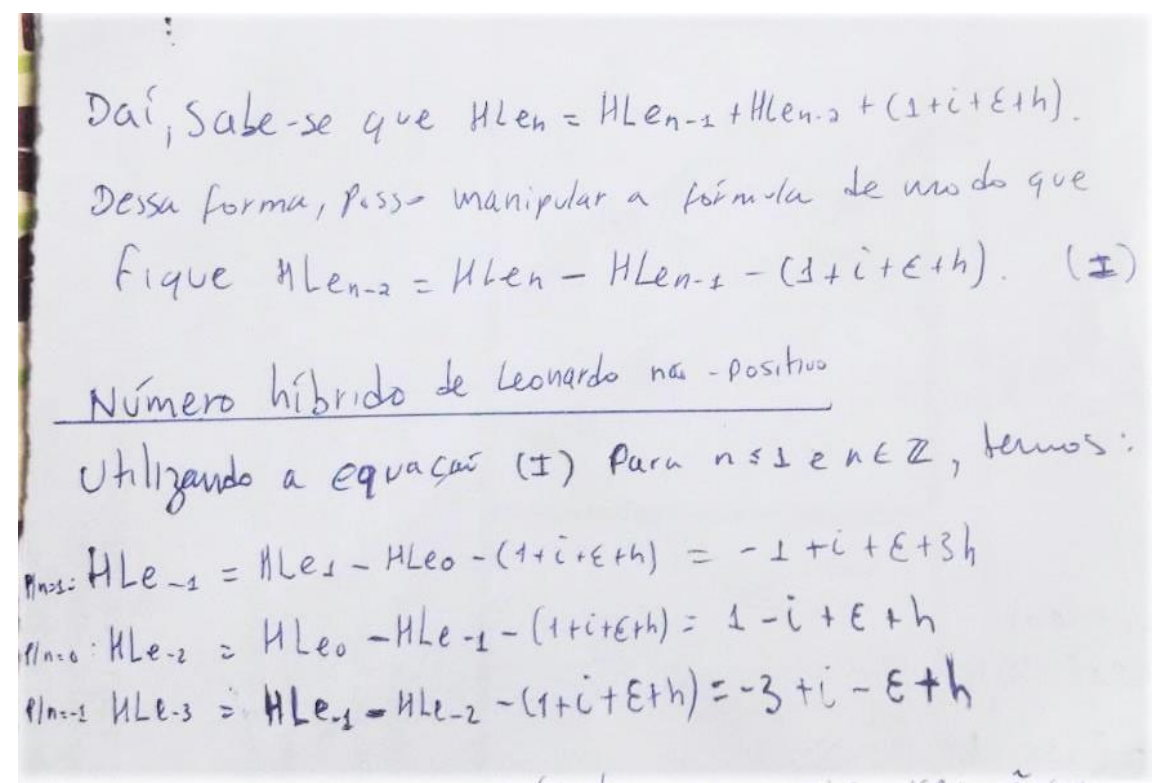

Figura 3: Fase de ação e formulação pelo aluno A- Situação-problema 1 Fonte: Dados da pesquisa.

Com isso, durante a fase de formulação o aluno A já havia identificado uma nova recorrência e, posteriormente, analisou se a partir desta fórmula era possível encontrar os termos desejados. Por fim, pode-se identificar na Figura 4 que o aluno A concluiu que essa recorrência é válida para os números híbridos não positivos de Leonardo.

Revista RBBA $\mid$ Revista Binacional Brasil Argentina Vol. 10, num. 2, dez/2021, p. 271-297 


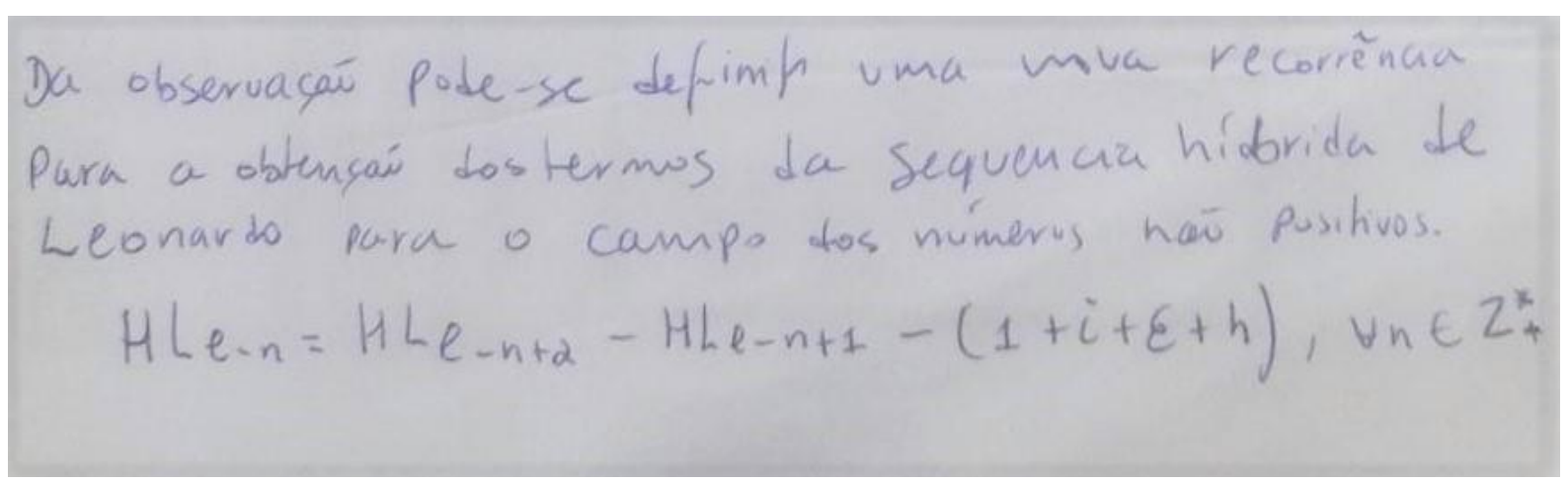

Figura 4: Fase de validação pelo aluno A- Situação-problema 1

Fonte: Dados da pesquisa.

Por outro lado, o aluno B teve mais dificuldade em obter os números híbridos negativos de Leonardo. Assim, o aluno B obteve outra estratégia de resolução, ele resolveu trabalhar a situação-problema 1 em três etapas. Inicialmente ele trabalhou com uma das recorrências da sequência de Leonardo, na qual ele percebeu que ao subtrair os termos anteriores desta sequência e o valor 1 foi possível obter seus termos negativos, como podemos ver na Figura 5.

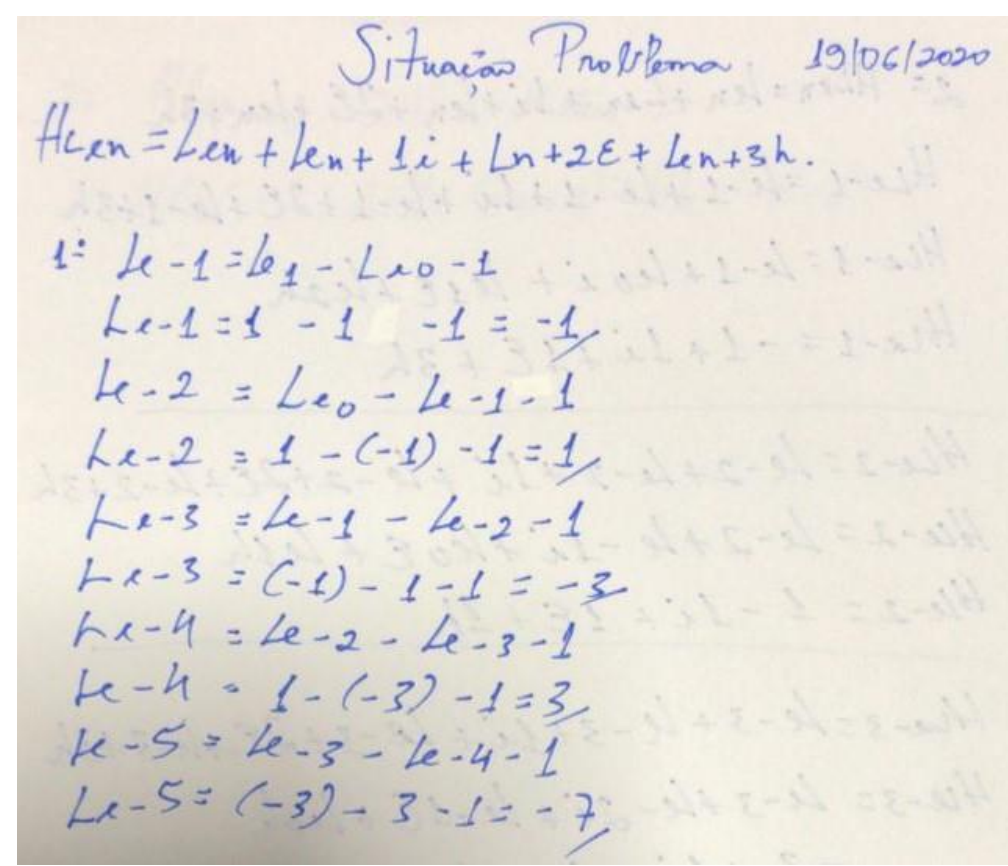

Figura 5: Fase de ação e formulação pelo aluno B- Situação-problema 1 Fonte: Dados da pesquisa.

Posteriormente, tendo ciência dos números negativos de Leonardo e da definição dos números híbridos, a qual foi apresentada inicialmente pelo professor, o aluno B realizou uma substituição dos termos negativos na definição dos números híbridos o que resulta nos números híbridos negativos de Leonardo, como podemos ver na Figura 6. 


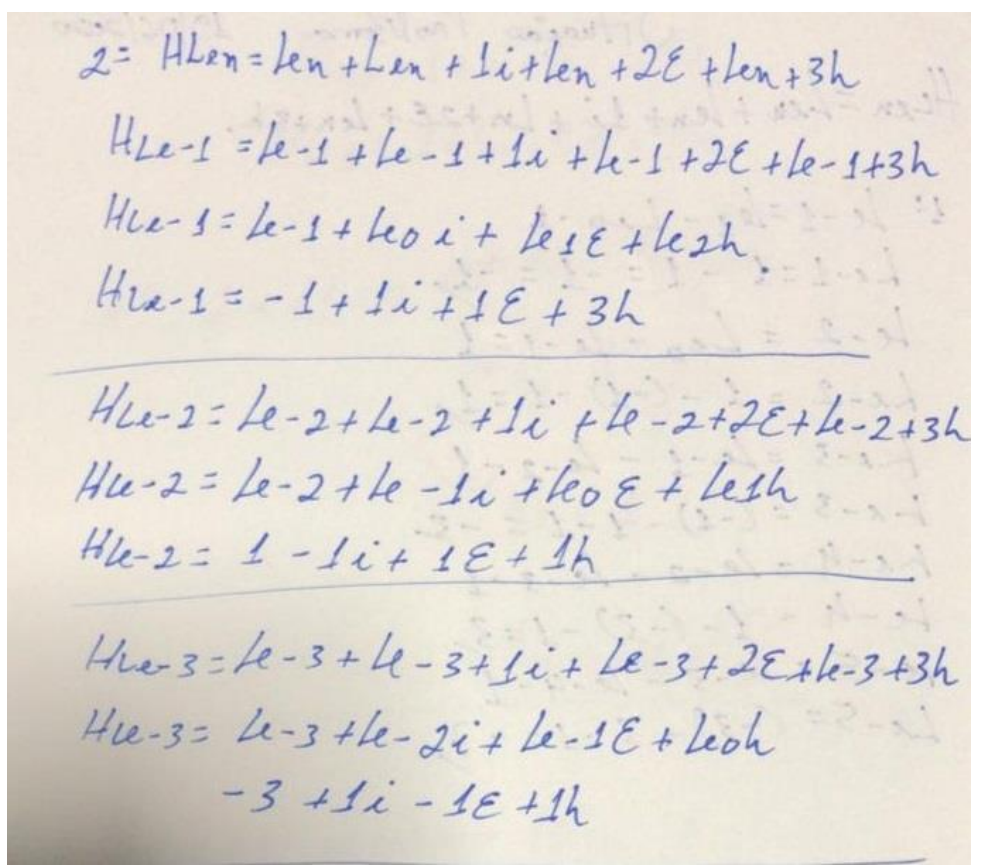

Figura 6: Fase de ação e formulação pelo aluno B- Situação-problema 1 Fonte: Dados da pesquisa.

Nesse sentido, para validar sua estratégia de solução, o estudante $\mathrm{B}$, a princípio, obteve dificuldade em obter a recorrência dos termos híbridos negativos, uma vez que ele tentou encontrar um padrão entre esses números e, por cada número híbrido obter quatro unidades, não conseguiu êxito. Assim, ele resolveu realizar manipulações algébricas a partir da recorrência dos números híbridos. Como podemos ver na Figura 7, o aluno B isolou o termo $H L e_{n-2}$, e ainda, inverteu o sinal e somou duas unidades em cada um dos índices. Após realizar essas manipulações, o aluno constatou que essa fórmula encontrada é uma das recorrências para os números híbridos de Leonardo não positivo.

$$
\begin{aligned}
\text { 3: Hlen }+1 & =2 \text { HLen }- \text { Hen }-2 \\
\text { Hle }(-n) & =2 \text { Hle }(-n+2)+\text { Hle }(-n+3)
\end{aligned}
$$

Figura 7: Fase de validação pelo aluno B- Situação-problema 1 Fonte: Dados da pesquisa 


\section{UMA EXPERIÊNCIA DA ENGENHARIA DIDÁTICA NO PROCESSO DE HIBRIDIZAÇÃO DA SEQUÊNCIA DE LEONARDO}

Dando continuidade, temos a resolução da situação-problema 2, em que os estudantes se deparam com duas fórmulas, a primeira é uma relação entre os números híbridos de Fibonacci com os números híbridos de Leonardo e a segunda é a fórmula de Binet dos números híbridos de Fibonacci. Tem-se como objetivo principal desta questão apresentar a fórmula de Binet dos números híbridos de Leonardo a partir das informações apresentadas no enunciado. Na Figura 8, a partir da fórmula de Binet dos híbridos de Fibonacci o aluno C apresenta como $H F_{n+1}$ se comporta e ainda, substitui o termo A por $H F_{1}-H F_{0} x_{2}$ e o termo B por $H F_{1}-H F_{0} x_{1}$.

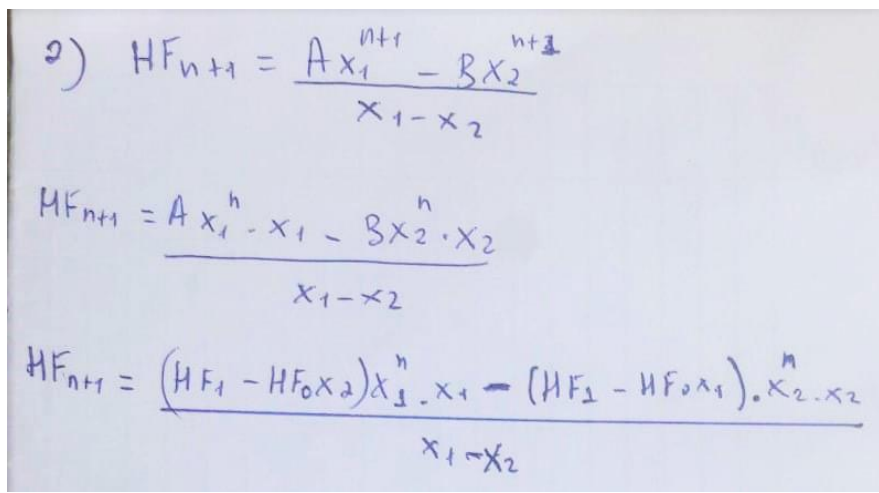

Figura 8: Fase de ação e formulação pelo aluno C- Situação-problema 2

Fonte: Dados da pesquisa

Após ter conhecimento do comportamento do $H F_{n+1}$, podemos ver na Figura 9 que o aluno A substituiu $H F_{n+1}$ na fórmula que relaciona os números híbridos de Fibonacci com os híbridos de Leonardo $\left(H L e_{n}=2 H F_{n+1}-(1+i+\varepsilon+h)\right.$ ) e realizou manipulações algébricas com o intuito de apresentar uma nova fórmula, a formula de Binet dos números híbridos de Leonardo.

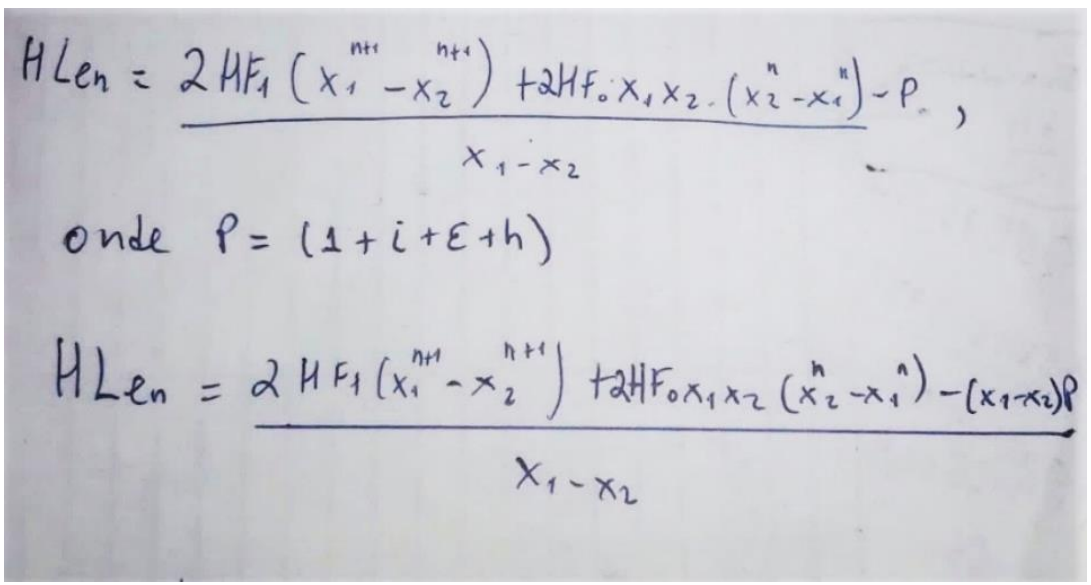

Figura 9: Fase de ação e formulação pelo aluno C- Situação-problema 2 Fonte: Dados da pesquisa.

Revista RBBA $\mid$ Revista Binacional Brasil Argentina Vol. 10, num. 2, dez/2021, p. 271-297 
Nesse sentido, para validar a estratégia de solução, o aluno D utilizou o princípio de indução finita, ou seja, verificou se a fórmula é válida para $n=1$ e para o número natural seguinte, $n+1$. A princípio, o estudante obteve dificuldade a validar esta fórmula, pois apresentava dificuldade em utilizar o método de indução, porém, após discussões entre os alunos, os estudantes conseguiram realizar a validação da fórmula de Binet para os números híbridos não positivos de Leonardo.

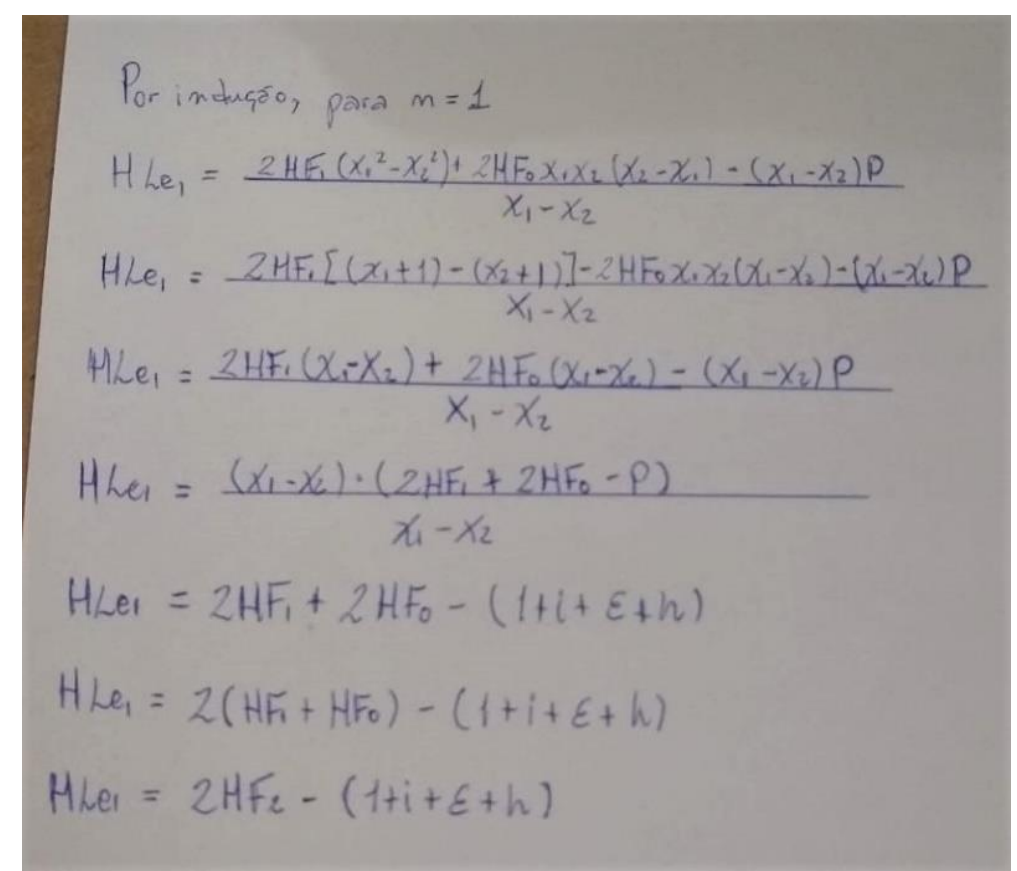

Figura 10: Fase de validação pelo aluno D- Situação-problema 2 Fonte: Dados da pesquisa.

Dando continuidade a fase de validação, tem-se na Figura 11 a segunda etapa do princípio da indução finita. 


\section{HIBRIDIZAÇÃO DA SEQUÊNCIA DE LEONARDO}

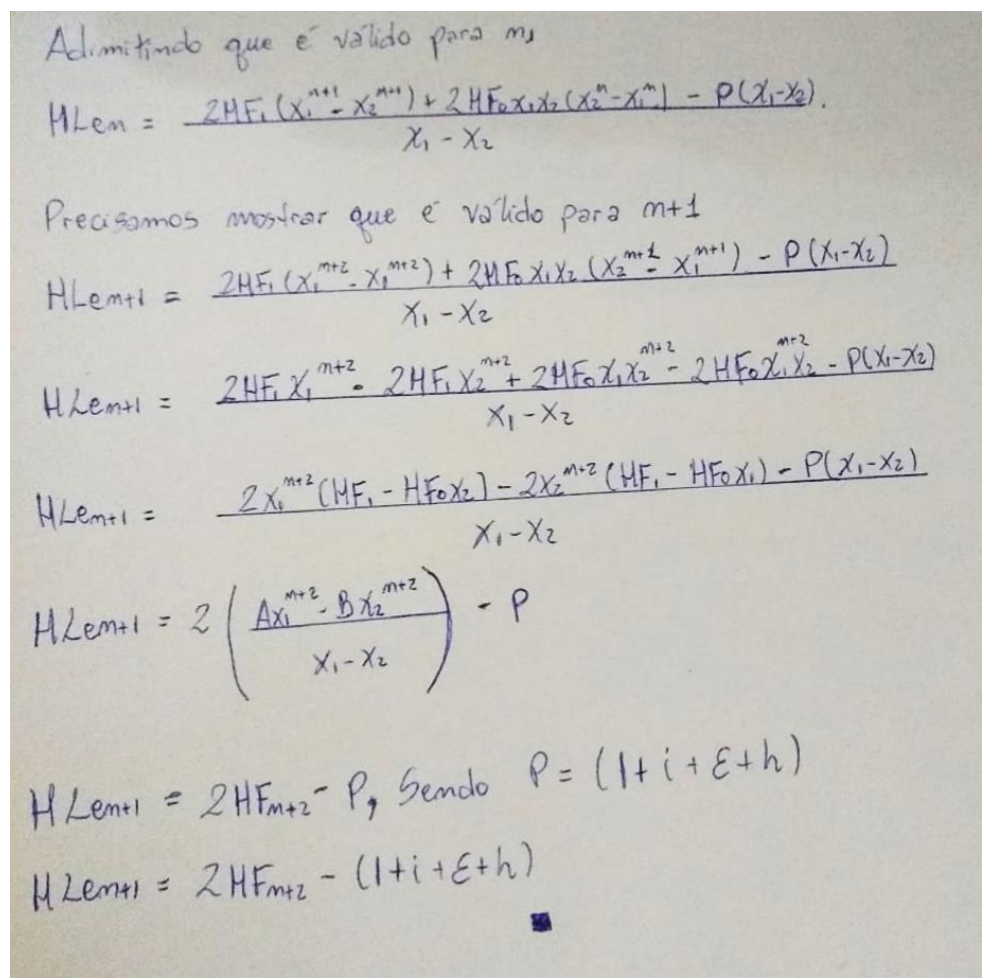

Figura 11: Fase de validação pelo aluno D- Situação-problema 2 Fonte: Dados da pesquisa.

Finalmente, a institucionalização foi realizada pelo professor ao final de cada resolução da situação-problema aplicado, analisando as soluções dos alunos explicitando e indicando as propriedades construídas a partir das fases anteriores. Percebe-se que na situação-problema 1 é oferecido duas recorrências distintas para a sequência híbrida de Leonardo. Assim, foi possível constatar que dois alunos utilizaram estratégias de resolução distintas, cada um utilizando um tipo de recorrência oferecida, porém apresentando os mesmos números híbridos não positivos de Leonardo, e ainda, duas novas recorrências válidas para esses números. Quanto a situaçãoproblema 2, foram identificados obstáculos epistemológicos e cognitivos, sendo a maior dificuldade no processo de validação da situação. Contudo, os alunos conseguiram finalizar as situações e entender o processo de hibridização da sequência de Leonardo e sua relação com os números híbridos de Fibonacci.

A validação desta pesquisa é feita internamente, uma vez que foram analisados somente os resultados obtidos da análise das situações didáticas aplicadas e do grupo de professores envolvidos. Vale salientar que, não foi realizado comparações dos dados coletados nesta pesquisa com produções externas, o que qualifica uma validação interna. Nesta fase de validação, foi realizado um confronto entre o que foi pré-definido na fase de análise a priori e com os resultados obtidos na fase de análise a posteriori, a partir da comparação entre as fases 
pode-se perceber que os alunos, conseguiram construir o processo de hibridização da sequência de Leonardo, expandindo para o campo dos inteiros não positivos, descobrindo novas definições e relacionando a outro conjunto de sequência hibridizada, e ainda, foram apontados aspectos cognitivos e didáticos.

Com isso, a partir das situações didáticas aplicadas, foi possível observar a efetivação do contrato didático entre professor e alunos, uma vez que, as situações foram abordadas numa perspectiva epistemológica referente ao processo de hibridização da sequência de Leonardo.

\section{AGRADECIMENTOS}

A parte de desenvolvimento da pesquisa no Brasil contou com o apoio financeiro do Conselho Nacional de Desenvolvimento Científico e Tecnológico (CNPq) e a Coordenação de Aperfeiçoamento de Pessoal de Nível Superior (CAPES).

A parte de desenvolvimento da pesquisa em Portugal é financiado por Fundos Nacionais através da Fundação para a Ciência e a Tecnologia. I. P (FCT), no âmbito o projeto UID/CED/00194/2020.

\section{CONSIDERAÇÕES FINAIS}

Este artigo apresenta uma parte da pesquisa que vem sendo realizada no PGECM-IFCE, com o parecer aprovado pelo Comitê de Ética em Pesquisa (CEP) (parecer: 4.141.910), na qual, investiga o processo de hibridização das sequências lineares recursivas, especificamente a sequência de Leonardo. A partir do campo-epistêmico matemático, encontrado no âmbito da Matemática Pura, foi realizado uma transposição didática dos teoremas e propriedades explorados para o plano pedagógico, com o intuito de transformar esses conceitos em um conteúdo a ser ensinado à uma turma de formação de professores do curso de Licenciatura em Matemática, na disciplina de História da Matemática. Ressalta-se que para realizar a aplicação das situações-problema durante o momento atual do país, foi utilizado o recurso tecnológico do Google Meet o que nos possibilitou dar continuidade as aulas da disciplina.

Desse modo, tem-se que na primeira fase do trabalho foi realizado um levantamento bibliográfico acerca da ED, TSD e ainda do objeto matemático, a hibridização da sequência de Leonardo. Posteriormente, foi realizado a experimentação prevista pela ED, na qual os alunos

Revista RBBA Revista Binacional Brasil Argentina Vol. 10, num. 2, dez/2021, p. 271-297 
perceberam o processo de hibridização da sequência ao relacionar a definição dos números híbridos, encontrando na Matemática Pura, com a sequência de Leonardo evidenciando seu processo histórico e evolutivo. Durante esta fase, os alunos formularam novas definições e exploraram teoremas matemáticos, e ainda, mesmo apresentando dificuldades na resolução e validação das situações, o objetivo geral deste trabalho foi alcançado.

Para pesquisas futuras, busca-se a aplicação deste estudo investigativo em outras instituições de ensino, das quais ofertem cursos de formação inicial de professores, podendo ainda realizar uma validação de forma externa, fundamentada na metodologia de pesquisa e na teoria de ensino utilizadas.

\section{REFERÊNCIAS}

ALMOULOUD, S. A.; COUTINHO, C. Q. S. Engenharia Didática: características e seus usos em trabalhos apresentados no GT-19/ANPEd. Revemat: Revista Eletrônica de Educação Matemática, v. 3, n. 1, p. 62-77, 2008. Disponível em: <https://doi.org/10.5007/19811322.2008v3n1p62>. Acesso em: 08 set. 2021.

ALMOULOUD, S. A. Fundamentos da didática da matemática. Editora UFPR, 2007.

ALVES, F. R. V.; MARINHO, M. R. M. Engenharia didática no contexto da transição complexa do cálculo-tcc: o caso da série de Laurent. Revista Eletrónica de Investigación em Educación en Ciencias, v. 12, n. 2, p. 63-89, 2017.

ALMOULOUD, S. A.; SILVA, M. J. F. da. Engenharia didática: evolução e diversidade didactic engineering: evolution and diversity. Revemat: Revista Eletrônica de Educação Matemática, v. 7, n. 2, p. 22-52, 2012.

ALVES, F. R. V. Engenharia Didática: implicações para a pesquisa no âmbito do ensino em análise complexa - ac. Ciência e Natura, v. 38, n. 2, p. 694-715, 2016.

ALVES, F. R. V.; VIEIRA, R. P. M.; CATARINO, P. M.; MANGUEIRA, M. M. Teaching recurrent sequences in Brazil using historical facts and graphical illustrations: an example of scientific cooperation Brazil x Portugal. Acta Didactica Naposcencia, v. 13, n. 1, p. 1 - 25, 2020 .

ARTIGUE, M. Didáctica de las matemáticas y reproducibilidad Mathematics Education and reproducibility. Educación Matemática, v. 30, n. 2, p. 9-32, 2018.

ARTIGUE, M. Perspectives on Design Research: The Case of Didactical Engineering. In: A. Bikner-Ahsbahs and C. Knipping, ed., Approaches to Qualitative Research in Mathematics Education Examples of Methodology and Methods, 1st ed. Springer Dordrecht Heidelberg, 467-496 2015. 
ARTIGUE, M. Didatical engineering as a framework for the conception of theaching products. In: Didactics of Mathematics as a discipline, 13 ed, Mathematics Education Library, 27-40, 2002.

ARTIGUE, M. Ingenieria Didática. Artigue, M., Douady, R., Moreno, L.; Gomez, P. In: Ingeniéria didatica en Educacion Matemática, 1995.

ARTIGUE, M. Ingénierie didactique. Recherches en Didactique des Mathématiques, v. 9, n. 3, p. 281-308, 1988.

BROUSSEAU, G. A etnomatemática e a teoria das situações didáticas. Educação Matemática Pesquisa, v. 8, n. 2, p. 267-281, 2006.

BROUSSEAU, G. Theory of Didactical Situationsin Mathematics Didactique de Mathématiques, 1970-1990. Mathematics Education Library, 19, 2002.

BROUSSEAU, G. Educacíon y didática de las matemáticas. Educacíon Matemática, v. 12, n. 1, p. $5-38,2000$.

BROUSSEAU, G. Theory of didactical situations in mathematics, Kluwer, 1997.

BROUSSEAU, G. Fundamentos e Métodos da Didáctica da Matemática. In: BRUN, J. Didática das Matemáticas. Tradução de: Maria José Figueiredo. Lisboa: Instituto Piaget, Cap. 1. 35-113, 1996.

BROUSSEAU, G. D'un problème à l'étude à priori d'une situation didactique. Deuxième École d'Été de Didactique des mathématiques, Olivet, 39-60, 1982.

CARVALHO, C. F. de. Números híbridos e sua visualização no GeoGebra. Dissertação, Mestrado Profissional em Rede Nacional do Centro de Ciências e Tecnologia, Universidade Estadual do Ceará, Fortaleza, 2019.

CATARINO, P. On k-pell hybrid numbers. Journal of Discrete Mathematical Sciences and Cryptography, p. 1-7, 2019.

CATARINO, P. M.; BORGES, A. On Leonardo numbers. Acta Mathematica Universitatis Comenianae, v. 89, n. 1, p. 75-86, 2019.

CERDA-MORALES, G. Investigation of generalized hybrid Fibonacci numbers and their properties. arXiv preprint arXiv:1806.02231, 2018.

CHEVALLARD, Y. La transposición didáctica: del saber sabio al saber enseñado. 3. ed., 1998.

FREITAS, J. L. M. d. Teoria das situações didáticas. In: MACHADO, Silvia Dias A. Educação matemática: uma (nova) introdução, Editora EDUC, 77-111, 2015.

Revista RBBA $\mid$ Revista Binacional Brasil Argentina Vol. 10, num. 2, dez/2021, p. 271-297 
KIZILATEŞ, C. A new generalization of Fibonacci hybrid and Lucas hybrid numbers. Chaos, Solitons \& Fractals, 130, 109449, 2020.

MANGUEIRA, M. C. dos S.; VIEIRA, R. P. M.; ALVES, F. R. V.; CATARINO, P. M. M. C. The Hybrid Numbers of Padovan and Some Identities. Annales Mathematicae Silesianae, v. 1, n. ahead-of-print, Sciendo, 2020.

MANGUEIRA, M. C. dos S.; ALVES, F. R. V.; CATARINO, P. M. M. C. Números híbridos de Mersenne. C.Q.D.-Revista Eletrônica Paulista de Matemática, v. 18, p. 1-11, 2020.

OLIVEIRA, R. R. de. Engenharia Didática sobre o Modelo de Complexificação da Sequência Generalizada de Fibonacci: Relações Recorrentes N-dimensionais e Representações Polinomiais e Matriciais. Dissertação, Mestrado em Ensino de Ciências e Matemática - Instituto Federal de Educação, Ciência e Tecnologia do Estado do Ceará, Fortaleza, 2018.

ÖZDEMIR, M. Introduction to hybrid numbers. Advances in Applied Clifford Algebras, v. 28, n. 1, p. 11, 2018.

PAIS, L. C. Didática da Matemática: uma análise da influência francesa. 2. ed. Editora Autêntica, 2002.

POMMER, W. M. A Engenharia Didática em sala de aula: Elementos básicos e uma ilustração envolvendo as Equações Diofantinas Lineares, 2013.

SOUZA, C. M. P.; LIMA, A. P. de A. B. O contrato didático a partir da aplicação de uma sequência didática para o ensino da progressão aritmética. Zetetiké-FE/Unicamp, v. 22, n. 42, p. 31-61, 2014.

SZYNAL-LIANA, A. The Horadam hybrid numbers. Discussiones Mathematicae-General Algebra and Applications, v. 38, n. 1, p. 91-98, 2018 a.

SZYNAL-LIANA, A.; WLOCH, I. On Pell and Pell-Lucas Hybrid Numbers.

Commentationes Mathematicae, v. 58, p. 1-2, 2018 b.

SZYNAL-LIANA, A.; WLOCH, I. On Jacobsthal and Jacobsthal-Lucas Hybrid Numbers. Annales Mathematicae Silesianae, p. 276-283, 2019.

TEMPIER, F. New perspectives for didactical engineering: an example for the development of a resource for teaching decimal number system. Journal of Mathematical Teacher Education, v. 19, n. 1, p. 261-276, 2016.

TEIXEIRA, P. J. M.; PASSOS, C. C. M. Um pouco da teoria das situações didáticas (tsd) de Guy Brousseau. Zetetike, v. 21, n. 1, p. 155-168, 2013.

VIEIRA, R. P. M.; ALVES, F. R. V.; CATARINO, P. M. M. C. Relações bidimensionais e identidades da sequência de Leonardo. Revista Sergipana de Matemática e Educação Matemática, v. 4, n. 2, p. 156-173, 2019. 